\title{
Kesiapsiagaan Siswa dalam Menghadapi Bencana Gempa Bumi dan Letusan Gunung Api Soputan(Studi Kasus pada SMA Negeri 1 Tombatu dan SD GMIMI 1 Silian)
}

\author{
Handy I R Moseya ${ }^{*}$, Charles E Mongi a, Hanny F Sangian a, Henkie F Woran b \\ aJurusan Fisika, FMIPA, Unsrat, Manado \\ bSMA Negeri 1 Tombatu
}

\begin{tabular}{l} 
K A T A K U N C I \\
\hline Mitigasi \\
Kesiapsiagaan bencana \\
Gempa Bumi \\
Letusan Gunung Api
\end{tabular}

\begin{abstract}
A B S T R A K
Telah dilakukan penelitian untuk mengetahui pengaruh penyuluhan dan sosialisasi pengetahuan tentang gempa bumi dan letusan gunung api terhadap kesiapsiagaan siswa menghadapi kedua bencana ini pada SMA Negeri 1 Tombatu dan SD GMIM 1 Silian. Penelitian ini menggunakan bersifat deskriptif yaitu penelitian yang bertujuan untuk melihat gambaran sebab dan akibat antar variabel penelitian tanpa membuat perbandingan atau menghubungkan dengan variabel lain. Sedangkan metode yang digunakan adalah metode survei dengan menggunakan kuesioner yang berisi pertanyaan terstruktur untuk mendapatkan informasi yang spesifik. Data tingkat pengetahuan dan keterampilan menyelamatkan diri dari bencana gempa bumi dan letusan gunung api didapatkan dari hasil pengisiankuesioner pretest dan posttest.. Hasil pengolahan data menunjukan nilai-P sebesar 0,001 dan nilai-T sebesar 3,76 untuk siswa SMA Negeri 1 Tombatu dan nilai-P sebesar 0,000 dan nilai-T sebesar 21,42 untuk siswa SD GMIM 1 Silian. Dari hasil ini dapat ditarik kesimpulan bahwa terdapat peningkatan tingkat pengetahuan dan keterampilan para siswa setelah mendapat penyuluhan dan pelatihan tentang kesiapsiagaan menghadapi bencana gempabumi dan letusan gunungapi
\end{abstract}

KEYW OR D S

Mitigation

Disaster Preparedness

Earthquake

Volcano Eruption

\begin{abstract}
A B S T R A C T
Research had been carried out to investigate the effect of disaster preparedness and mitigation counseling to students in Tombatu Public High School (SMA Negeri 1 Tombatu) and GMIM Elementary Private School in Silian (SD GMIM 1 Silian). Descriptive survey was used in this research by using questionnaire that contained structured question to get specific information needed for this research. The students knowledge and skill for surviving earthquake and volcanic eruption are measured with pretest and posttest questionnaire. The result obtained from questionnaire shows that P-value is 0,001 and T-value is 3.76 for students in SMA Negeri 1 Tombatu and P-value is 0,000 and T-value is -21.42 for students in SD GMIM 1 Silian. From this result we conclude that disaster preparedness and mitigation counseling can give significance to students knowledge and skill for surviving earthquake and volcanic eruption.
\end{abstract}

TERSEDIA ONLINE

01 Februari 2019

1. Pendahuluan

Sulawesi Utara merupakan wilayah yang dilalui jalur gempa Pasifik dan cincin api (ring of fire). Keadaan tersebut membuat wilayah ini rentan terhadap bencana alam terutama letusan gunung api, gempa bumi dan
Tsunami (Tondobala, 2011). Letusan gunungapi merupakan bencana alam yang dapat mengancam dan menggangu kehidupan masyarakat karena mengakibatkan timbulnya korban jiwa manusia, kerusakan lingkungan, kerugian harta benda dan ternak serta dampak psikologis (Ilham dan Priyanti, 2011).

*Corresponding author: Jurusan FisikaFMIPA UNSRAT, Jl. Kampus Unsrat, Manado, Indonesia 95115; Email address: cici.heijie@gmail.com, hirmosey@unsrat.ac.id

Published by FMIPA UNSRAT (2019) 
Menurut David dkk, (2015) Gunung Soputan termasuk salah satu dari 129 gunung api aktif di Indonesia. Gunung Soputan merupakan bagian dari sistim Busur Kepulauan Sangihe terkait dengan zona tumbukan Laut Maluku yang terletak pada persimpangan lempeng Eurasia, Pasifik, dan Filipina. Secara geografis terletak gunung Soputan terletak pada posisi $1^{\circ} 06^{\prime} 30$ "LU dan $124^{\circ} 44^{\prime} 00^{\prime \prime B T}$ dengan ketinggian 1784 mdpl (Kushendratno et al, 2012). Secara Administratif, gunung Soputan berada di Kabupaten Minahasa Tenggara, Propinsi Sulawesi Utara (Badan Geologi, 2010), berada di tepi selatan kaldera Gunung Tondano tercatat pertama kali meletus pada ratusan tahun lalu, tepatnya di tahun 1785 (Suparman dkk, 2011).

Kecamatan Tombatu adalah salah satu kecamatan di Kabupaten Minahasa Tenggara, berjarak sekitar 90 $\mathrm{km}$ dari kota Manado, Sulawesi Utara. Kecamatan Tombatu memiliki luas wilayah $192,55 \mathrm{~km}^{2}$. Total jumlah penduduknya 9875 jiwa. SMA Negeri 1 Tombatu terletak dalam radius $9 \mathrm{~km}$ dari puncak gunung Soputan (Gambar 1).Desa Silian merupakan satu dari 10 desa yang berada di kecamatan Silian Raya. Desa ini berjarak 22,2 km dari ibukota kabupaten Minahasa Tenggara, Ratahan. Secara geografis, Desa Silian terletak pada $1^{\circ} 03^{\prime} 46.0^{\prime \prime}$ LU $124^{\circ} 40^{\prime} 01.7^{\prime \prime}$ BT. Desa Silian terletak sekitar 9-10 km sebelah Barat Daya dari kawah gunung Soputan. Sekolah Dasar GMIM 1 Silian terletak di desa Silian kecamatan Silian Raya, Kabupaten Minahasa Tenggara, provinsi Sulawesi Utara (Gambar 2).

Dari sejarahnya, Gunung Soputan sendiri adalah gunung api yang sangat aktif. Dari penelusuran melalui laman Pusat Vulkanologi dan Mitigasi Bencana Geologi (PVMBG), Soputan merupakan salah satu gunung api aktif dengan tipe Stratovolcano yang terletak di Minahasa Tenggara dengan koordinat $1^{\circ} 06^{\prime} 30.0^{\prime \prime}$ Lintang Utara dan $124^{\circ} 43^{\prime} 01.7^{\prime \prime}$ Bujur Timur (Sinaga, et al, 2017). Berdasarkan data yang diperoleh dari Koeshendratno et al, (2012) dan Seach (2016), gunung Soputan meletus pada tahun 1785, 1819, 1833, 1845, 1890, 1901, 1906, 1907, 1908, 1909, 1910, 1911, 1912, 1913, 1915, 1917, 1923, 1924, 1947, 1953, 1966, 1967, 1968, 1970, 1971, 1973, 1982, 1984, 1985, 1989, 1991, 1996, 2000-03, 2004, 2005, 2007, 2008, 2011, 2012, 2015, 2016.

Kesiapsiagaan bencana gempabumi dan letusan gunung api Soputan di SMA Negeri 1 Tombatu dan SD GMIM 1 Silian sangat diperlukan untuk mengurangi risiko, mengantisipasi, mengurangi dampak kerugian dan jatuhnya korban di lingkungan sekolah. Fakta di lapangan menunjukan bahwa tidak semua siswa dan guru mempunyai pengetahuan dan kemampuan yang cukup tentang kedua bencana ini.Hal ini dikarenakan belum mendapat sosialisasi dari lembaga yang terkait tentang kesiapsiagaan bencana gempabumi dan letusan gunungapi. Tujuan penelitian ini adalah untuk mengetahui tingkat pengetahuan dan keterampilan siswa guru terhadap bencana gempabumi dan gunungapi di SMA Negeri 1 Tombatu dan SD GMIM 1 Silian.

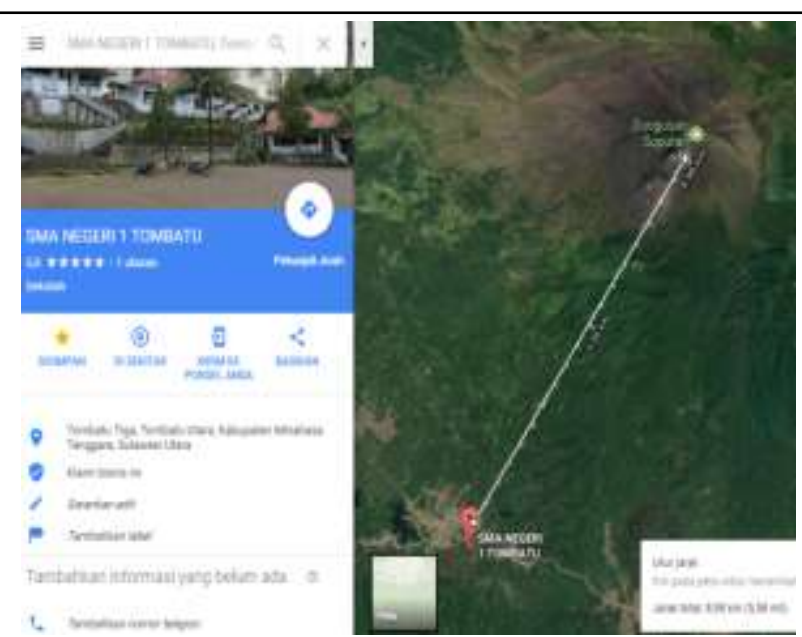

Gambar 1.Jarak SMA Negeri 1 Tombatu dalam radius 9 km dari puncak gunung Soputan. (maps.google.com)

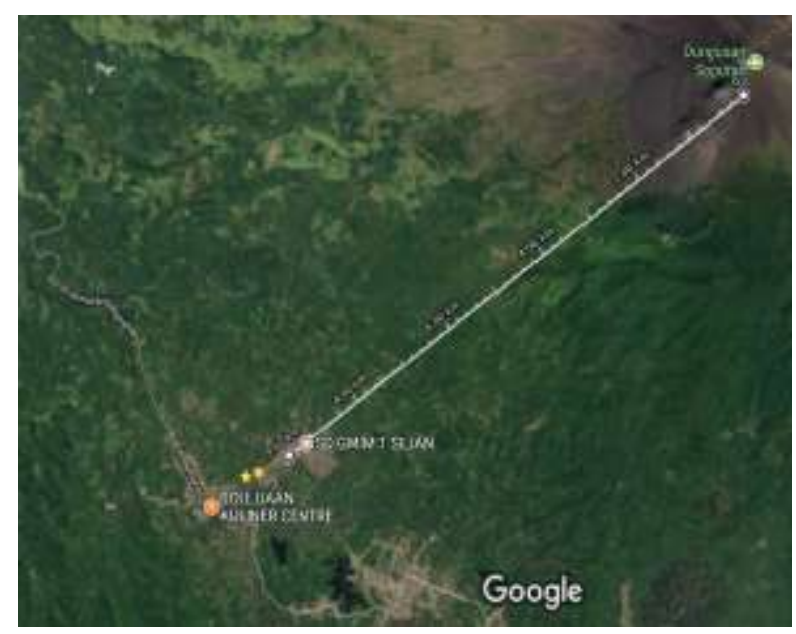

Gambar 2.Jarak SD GMIM 1 Silian dalam radius 9 km dari puncak gunung Soputan. (maps.google.com)

\section{Material dan Metode}

Penelitian deskriptif dilakukan dengan tujuan untuk mendapatkan gambaran tentang variabel penelitian baik satu variabel atau lebih tanpa membuat perbandingan atau menghubungan dengan variabel lain (Sugiyono,2004:11). Penelitian ini adalah jenis deskriptif sehingga dilakukan melalui pengumpulan data di lapangan. Metode penelitian yang digunakan adalah dua metode survey yaitu : descriptive survey dan explanatory survey. Instrumen pokok yang digunakan dalam pengumpulan data di lapangan adalah kuesioner.Kuesioner ini terdiri atas 15 pertanyaan tentang bencana gempabumi dan letusan gunungapi. Unit analisis dalam penelitian ini adalah individual yaitu siswa-siswa SMA Negeri 1 Tombatu dan SD GMIM 1 Silian, khususnya pada siswa SMA kelas XII program Matematika dan IImu Alam (MIA) dan siswa SD kelas 46.Peneliti melakukan pretest dan posttest yakni melalui pengisian kuesioner untuk siswa-siswa yang berada pada kedua sekolah tersebut mengenai materi pendidikan siaga bencana dan mitigasi tentang gempabumi dan letusan gunungapi. Pretest dilakukan sebelum para siswa menerima materi dan posttest diberikan setelah para siswa menerima materi. Materi yang diberikan yakni pengetahuan tentang fenomena 
gempabumi dan letusan gunungapi serta mitigasi kedua bencana alam tersebut (latihan/simulasi siaga gempa, identifikasi tempat yang berbahaya dan yang aman).Selanjutnya data diolah dengan menggunakan bantuan perangkat lunak Microsoft Excel 2007 dan Minitab v.18.

\section{Hasil dan Pembahasan}

Secara umum, dari hasil pretest dan posttest dapat terlihat adanya peningkatan pengetahuan dan keterampilan para siswa tentang fenomena bencana gempa bumi dan letusan gunungapi, tindakan mitigasi dan tanggap darurat ketika menghadapi kedua bencana ini. Data pretest dan posttest berdasarkan 24 responden dari siswa SMA N. 1 Tombatu yang telah mengisi kuesioner disajikan pada gambar 3 .

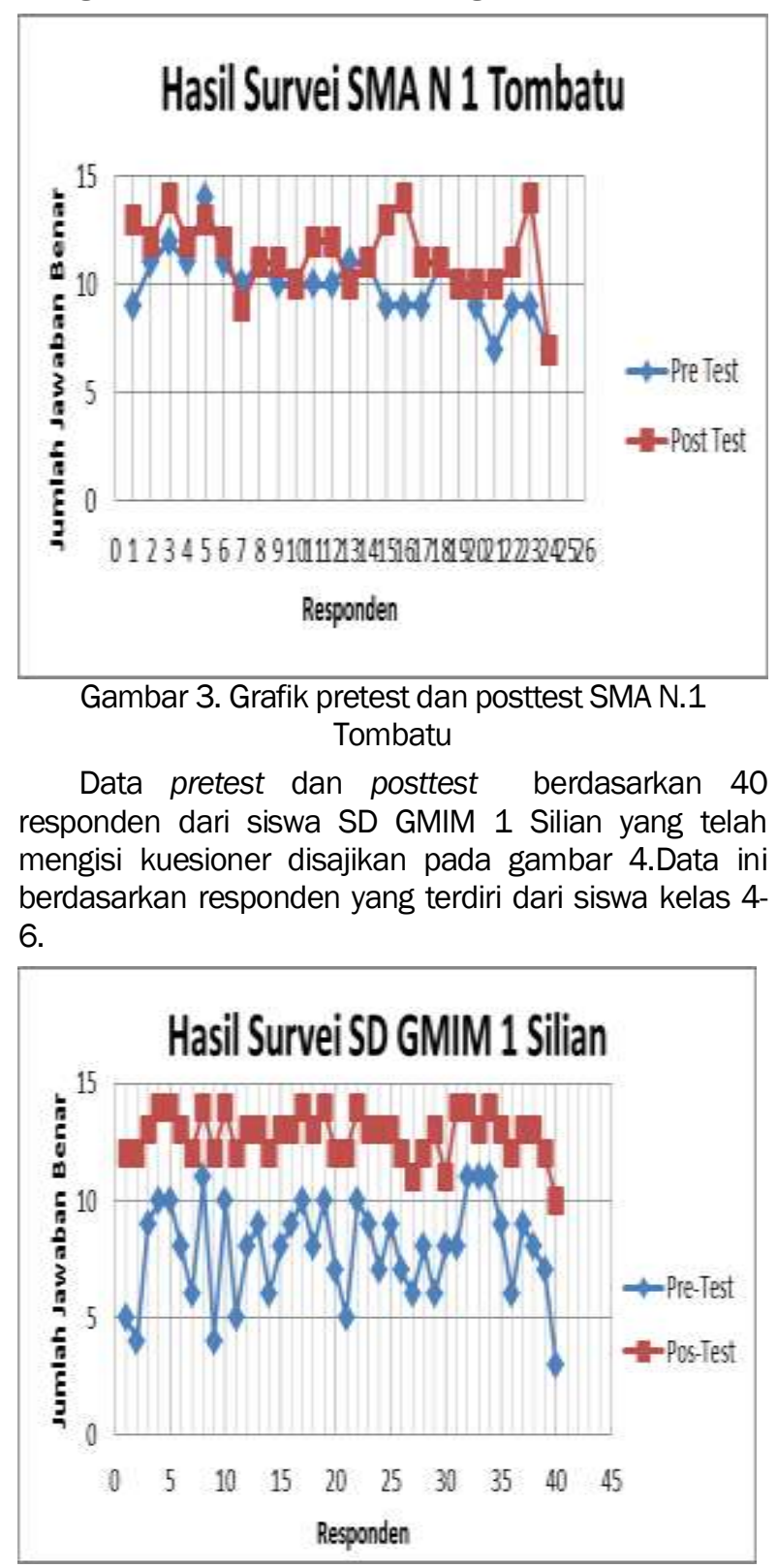

Gambar 4. Grafik pretest dan posttest SD GMIM 1 Silian

Hasil pengolahan data menunjukan nilai-P sebesar 0,001 dan nilai-T sebesar 3,76 untuk siswa SMA Negeri 1 Tombatu dan nilai-P sebesar 0,000 dan nilai-T sebesar -21,42 untuk siswa SD GMIM 1 Silian.

\section{Kesimpulan}

Dari hasil yang didapat melalui pengisian pretest dan posttestini dapat ditarik kesimpulan bahwa terdapat peningkatan tingkat pengetahuan dan keterampilan para siswa setelah mendapat penyuluhan dan pelatihan tentang kesiapsiagaan menghadapi bencana gempabumi dan letusan gunungapi.

Tim peneliti dan Mitra Program Kemitraan Masyarakat (SMA N. 1 Tombatu) dan SD GMIM 1 Silian mengucapkan banyak terima kasih kepada Direktorat Riset dan Pengabdian Masyarakat Direktorat Jenderal Penguatan Riset dan Pengembangan Kementrian Riset, Teknologi dan Pendidikan Tinggi yang sudah mendanai Pelaksanaan Program Kemitraan Masyarakat (PKM) ini. Peneliti juga mengucapkan terima kasih kepada Prof. John Kekenusa,MS atas diskusi ilmu Statistika yang sangat bermanfaat.

\section{Daftar Pustaka}

Badan Geologi. 2010. Keiapsiagaan Menghadapi Bencana Erupsi Gunung api.

BPS Minsel. 2016. Kecamatan Tombatu Dalam Angka 2016. BPS Kabupaten Minahasa Selatan. Katalog BPS: 1102001.7109050. No. Publikasi :71050.1626

David,S., Ferdy., Pasau, G. 2015. Penentuan Lokasi Pergerakan Magma Gunung Api Soputan Berdasarkan Studi Sebaran Hiposenter Gempa Vulkanik Periode Mei 2013- Mei 2014. Jurnal IImiah Sains 2(2):88-93.

Ilham, N dan Priyanti, A. 2011. Dampak Bencana Merapi Terhadap Usaha Sapi Perah Di Kabupaten Sleman. Jurnal WARTAZOA 21 (4):161-170.

Kushendratno, Pallister,J.S., Kristianto, Bina,F.R., McCausland. (2012). Recent Explosive Eruptions and Volcano Hazards at Soputan Volcano-A Basalt Stratovolcano in North Sulawesi, Indonesia. Bull Volcano 74:15811609.

Mais, P. R., Mulyadi., Lolong, J. 2015. Pengaruh Penyuluhan Bahaya Gunung Berapi Terhadap Kesiapsiagaan Siswa SMP Kristen Kakaskasen Kota Tomohon Menghadapi Bencana Gunung Berapi. Ejournal Keperawatan (e-Kep). 3(2): 1-6.

(Sugiyono,2004:11)

Suparman, Y., Kriswati, E., Pamitro, Y.E. (2011). Mekanisme Sumber Gempa Dangkal Frekuensi Tinggi di Gunung Soputan, Sulawesi Utara. Jurnal Geologi Indonesia,. 6 (3): 135-144

Tondobala, L. 2011. Pemahaman Tentang Kawasan Rawan Bencana dan Tinjauan Terhadap Kebijakan dan Peraturan Terkait. Jurnal Sabua 3(1) : 58-63. 